\title{
Substratos para testes de emergência de plântulas e vigor de sementes de Erythrina velutina Willd., Fabaceae
}

\section{Substrate for tests of seedlings emergency and seed vigor of Erythrina velutina Willd., Fabaceae}

\author{
Edna Ursulino Alves ${ }^{1 *}$; Leonaldo Alves de Andrade ${ }^{1}$; Heloisa Helena de Araújo \\ Barros $^{1}$; Edilma Pereira Gonçalves ${ }^{2}$; Anarlete Ursulino Alves ${ }^{3}$; Gerlândio Suassuna \\ Gonçalves ${ }^{4}$; Lamartine Soares Bezerra de Oliveira ${ }^{4}$; Edson de Almeida Cardoso ${ }^{4}$
}

Resumo

Com o objetivo de avaliar a influência de diferentes substratos na emergência e desenvolvimento de plântulas de Erythrina velutina Willd. foi conduzido um experimento em casa de vegetação pertencente ao Laboratório de Ecologia Vegetal do Centro de Ciências Agrárias da Universidade Federal da Paraíba. Foram comparados os substratos areia lavada; areia lavada + vermiculita na proporção de 1:1, 3:1 e 1:3; terra vegetal, terra vegetal + areia lavada na proporção de 1:1, 3:1 e 1:3, terra vegetal + vermiculita na proporção de 1:1,3:1 e 1:3, vermiculita, bioclone $\AA$, bioplant ${ }^{\circledR}$ e plugmix ${ }^{\circledR}$. O delineamento utilizado foi o inteiramente casualizado com 15 tratamentos (substratos) e quatro repetições de 25 sementes. Foram avaliados os seguintes parâmetros: porcentagem de emergência, primeira contagem, índice de velocidade, tempo médio e frequência relativa de emergência, comprimento e massa seca da raiz e parte aérea das plântulas. Constatou-se que os substratos areia e vermiculita foram responsáveis pelos melhores desempenhos, sendo recomendados para condução de testes de emergência de plântulas de mulungu. Palavras-chave: Mulungu, germinação, espécie medicinal

\begin{abstract}
This research work had as objective to evaluate the effect of different substrates on emergence and seedlings development of Erythrina velutina Willd. The experiment was carried out at the greenhouse of the Laboratory of Vegetable Ecology in the Center of Agrarian Sciences - Federal University of Paraíba. The substrates evaluated were washed sand; washed sand + vermiculite in the proportions of $1: 1,3: 1$ and 1:3; vegetable earth, vegetable earth + washed sand in the proportions of $1: 1,3: 1$ and 1:3, vegetable earth + vermiculite in the proportions of $1: 1,3: 1$ and $1: 3$, vermiculite, bioclone ${ }^{\circledR}$, bioplant ${ }^{\circledR}$ and plugmix ${ }^{\circledR}$. The experimental design was completely randomized with fifteen treatments (substrates) and four replications of 25 seeds. The effect was evaluated through percent of emergence, first count, emergence velocity index, medium time and relative frequency of emergency, length and dry mass of the root and it leaves aerial of the seedling. The substrates sand and vermiculite had the best results and are recommended for conduction of tests of emergency of mulungu seedlings.
\end{abstract}

Key words: Mulungu, germination, medicinal specie

1 Professores do CCA-UFPB, Depto. de Fitotecnia, Areia-PB; ednaursulino@cca.ufpb.br; landrade@cca.ufpb.br.

2 Bolsista PRODOC-CAPES. CCA-UFPB, Areia-PB.

3 Aluna do Programa de Pós-Graduação em Agronomia. CCA-UFPB, Areia-PB.

4 Alunos do Curso de Graduação em Agronomia. CCA-UFPB, Areia-PB.

* Autor para correspondência

Recebido para publicação 07/02/07 Aprovado em 30/07/07 


\section{Introdução}

Erythrina velutina Willd. (Fabaceae), popularmente conhecida como mulungu ocorre em indivíduos isolados na comunidade ou, em alguns casos, em grupos pouco densos, é uma planta espinhenta, de 8 a 12 metros, comum nas caatingas, onde atinge pontos bem distantes, porém não lhes sendo exclusiva, tendo dispersão mais ligada às subáreas úmidas das margens de rios. Por outro lado, fora das caatingas, sua área de dispersão inclui a várzea fluvio-marinha do Recife, Minas Gerais, Rio de janeiro e São Paulo e, mais ainda, Antilhas, norte da Venezuela, norte da Colômbia, Equador, Ilhas Galápagos e Peru (LORENZI, 2002).

O mulungu tem diversas aplicações, a árvore é extremamente ornamental, principalmente quando em flor, o que tem estimulado seu emprego no paisagismo, especialmente na arborização de ruas, jardins e alamedas (KURIHARA; IMAÑA-ENCINAS; PAULA, 2005). Na zona sul da Bahia, onde foi introduzido, é usado, com bons resultados, no sombreamento dos cacaueiros e como cerca viva. Além dessas utilidades a sua madeira pode servir para a confecção de palitos de fósforo, tamancos, jangadas, brinquedos, caixotarias e, com frequência é usado para mourões de cerca, pela facilidade do seu plantio por estacas.

Essa espécie nativa da flora brasileira tem sido utilizada na medicina popular em algumas regiões do Nordeste brasileiro. São atribuídas às infusões da casca propriedades sudorífica, calmante, emoliente, peitoral e do seu fruto seco ação anestésica local que é usado na forma de cigarro como odontálgico, embora a eficácia e segurança de seu uso ainda não tenham sido confirmadas cientificamente (LORENZI; MATOS, 2002). Dantas et al. (2004) evidenciaram que o extrato aquoso das folhas de E. velutina em baixas doses interferiu em processos mnemônicos e, em doses maiores agiu como sedativo e bloqueador neuromuscular periférico. Por sua vez, Virtuoso et al. (2005) constataram sua atividade contra o Staphylococcus aureus e Streptococcus pyogenes.
Informações sobre sementes florestais, especialmente no que diz respeito à padronização e ao aperfeiçoamento de métodos de análise têm sido motivos de estudo por parte de pesquisadores e analistas de sementes, em função da inexistência de prescrições para a condução de teste de germinação para espécies florestais nativas (OLIVEIRA; PIÑARODRIGUES; FIGLIOLIA, 1989). De acordo com Marcos Filho (1986), a germinação é um fenômeno biológico cuja ocorrência é determinada por um conjunto de condições específicas, dentre as quais se insere o substrato. Carvalho e Nakagawa (2000) acrescentam que as atividades metabólicas da semente e que culminam com a efetiva retomada de crescimento pelo eixo embrionário se aceleram a medida que a semente, posta no substrato apropriado, absorve água.

Os tipos de substratos mais utilizados, descritos e prescritos em Brasil (1992) são: pano, papel toalha, papel de filtro, papel mata borrão, terra vegetal e areia, devendo estar adequadamente úmidos para que forneçam às sementes a quantidade de água necessária à germinação.

A padronização de testes de germinação visa à uniformidade dos resultados, permitindo a comparação entre diferentes laboratórios (ANDRADE et al., 1999). Por isso, estudos sobre o efeito do substrato são necessários para obtenção de plântulas de melhor qualidade (CAMPOS; UCHIDA, 2002).

Segundo Brasil (1992), a areia e o solo estão entre os substratos mais usados para o teste de germinação. No entanto, Hartmann et al. (1997) relataram que o solo deve atender a certos requisitos de textura e estrutura, bem como apresentar uma boa composição das fases sólida, líquida e gasosa, de modo a permitir um desempenho satisfatório das sementes, enquanto a areia é um substrato que não contêm nutrientes nem apresenta propriedades coloidais. A serragem e a vermiculita, embora não estejam prescritas nas Regras para Análise de Sementes, são amplamente usadas em experimentos, tanto para testes de germinação quanto para análise de crescimento. 
Para sementes de espécies florestais, muitos substratos têm sido testados na condução de testes de germinação, tais como carvão, esfagnum, vermiculita, pano, papel toalha, papel de filtro, papel mata borrão, terra vegetal, areia, entre outros (ALBUQUERQUE et al., 1998; ANDRADE et al., 1999; BILIA; BARBEDO; MALUF, 1998; TORRES; MELLO, 1994).

Em sementes de Caesalpinia pelthophoroides Benth., o substrato areia não foi indicado para condução de testes de germinação (SCALON et al., 2003). No entanto, o referido substrato foi indicado para sementes de Podocarpus lambertii Klotzch Ex NDL (MEDEIROS; ZANON, 1998), Peltophorum dubim (Spreng) Taubert (PEREZ; FANTI; CASALI, 1999), Tabebuia serratifolia (Vahl) Nicholson (MACHADO et al. 2002), Hancornia speciosa Gomes (NOGUEIRA; ALBUQUERQUE; SILVA JUNIOR, 2003), Rollinia mucosa (Jacq.) Baill (SANTOS; ROBERTO; MARTINS, 2005), Solanum sessiliflorum Dunal (LOPES; PEREIRA, 2005) e de Drimys brasiliensis Miers (ABREU; NOGUEIRA; MEDEIROS, 2005).

O substrato vermiculita foi recomendado para testes de germinação em sementes de Acosmium nitens (Vog.) Yakovlev (VARELA; COSTA; RAMOS, 2005), Dalbergia nigra (Vell.) Fr. All. Ex Benth (ANDRADE et al., 2006). Para Ziziphus joazeiro Mart., o substrato vermiculita misturado + terra vegetal foi o mais indicado (MONIZ-BRITO; AYALA-OSUÑA, 2005). Em contrapartida, Iossi et al. (2003) não recomendaram a vermiculita como substrato para testes de vigor de sementes e avaliação das plântulas de Phoenix roebelenii O'Brien.

Estudos realizados por Bezerra et al. (2002) com sementes de Momordica charantia L. indicaram os substratos areia, solo e plugmix ${ }^{\circledR}$ como adequados para condução de testes de germinação. Carvalho Filho et al. (2003) também recomendaram a mistura de substratos contendo solo + areia + esterco (1:2:1) para a emergência e desenvolvimento inicial de plântulas de Hymenaea courbaril L.
Em razão da escassez de estudos no que se refere à padronização do teste de germinação em espécies de caráter medicinal e ornamental e do grande potencial econômico do mulungu, o presente trabalho teve como objetivo avaliar o efeito de diferentes substratos na capacidade germinativa e no vigor de sementes desta árvore em condições de casa de vegetação.

\section{Material e Métodos}

O trabalho foi realizado durante dez dias em casa de vegetação pertencente ao Laboratório de Ecologia Vegetal do Centro de Ciências Agrárias da Universidade Federal da Paraíba, em Areia - PB $6^{\circ} 58^{\prime} 12^{\prime \prime S}$ e $35^{\circ} 42^{\prime} 15^{\prime \prime} \mathrm{W}$ e $574,62 \mathrm{~m}$. A região apresenta temperatura média anual entre $23-24{ }^{\circ} \mathrm{C}$ e precipitação anual de $1.400 \mathrm{~mm}$.

As sementes de mulungu foram coletadas diretamente do chão, em dez árvores com características fenotípicas de matrizes no município de Areia, entre março e abril de 2006. Após a coleta, estas foram acondicionadas em sacos de papel e permaneceram no Laboratório de Análise de Sementes, sob condições ambientais até a instalação do experimento (30 dias).

$\mathrm{O}$ delineamento experimental utilizado foi $\mathrm{o}$ inteiramente ao acaso e os dados obtidos, não transformados, foram submetidos à análise de variância pelo teste $\mathrm{F}$ e as médias comparadas pelo teste de Scott Knott, a $5 \%$ de probabilidade. Foram utilizadas 100 sementes por tratamento, divididas em quatro repetições de 25 unidades cada uma.

As sementes apresentam impermeabilidade do tegumento a água e, por isto foram submetidas à escarificação manual com lixa d'água $\mathrm{n}^{\circ} 80$ na região oposta a da emissão da radícula, as sementes foram semeadas em bandejas plásticas perfuradas no fundo, com dimensões de $29 \times 22 \times 10 \mathrm{~cm}$ de comprimento, largura e profundidade, respectivamente, entre os seguintes substratos esterilizados em autoclave: areia lavada $\left(\mathrm{T}_{1}\right)$; areia lavada + vermiculita na proporção de 1:1 $\left(\mathrm{T}_{2}\right), 3: 1\left(\mathrm{~T}_{3}\right)$ e 1:3 $\left(\mathrm{T}_{4}\right)$; terra vegetal $\left(\mathrm{T}_{5}\right)$, 
terra vegetal + areia lavada na proporção de 1:1 $\left(\mathrm{T}_{6}\right)$, 3:1 $\left(\mathrm{T}_{7}\right)$ e $1: 3\left(\mathrm{~T}_{8}\right)$, terra vegetal + vermiculita na proporção de $1: 1\left(\mathrm{~T}_{9}\right), 3: 1\left(\mathrm{~T}_{10}\right)$ e $1: 3\left(\mathrm{~T}_{11}\right)$, vermiculita $\left(T_{12}\right)$, bioclone ${ }^{\circledR}\left(T_{13}\right)$, bioplant ${ }^{\circledR}\left(T_{14}\right)$ e plugmix ${ }^{\circledR}\left(\mathrm{T}_{15}\right)$. Foram utilizadas 100 sementes por tratamento, divididas em quatro repetições de 25 . Para avaliação do efeito dos tratamentos determinouse os seguintes parâmetros:

Porcentagem de Emergência - as contagens do número de sementes emergidas iniciaram-se aos quatro dias e estenderam-se até os dez dias após a semeadura, considerando-se como critério de avaliação, as plântulas que apresentavam os cotilédones acima do solo. Os resultados expressos em porcentagem; primeira contagem de emergência - correspondente à porcentagem acumulada de plântulas normais, com valores registrados a partir do quinto dia após o início do teste; índice de velocidade de emergência (IVE) - realizou-se contagens diárias das plântulas normais emergidas durante dez dias, cujo índice foi calculado conforme a fórmula proposta por Maguire (1962); tempo médio e frequência relativa de emergência - avaliados de acordo com Labouriau e Valadares (1976); comprimento de plântulas - dez dias após a semeadura as plântulas normais foram retiradas das bandejas, os cotilédones removidos e medidos o comprimento da raiz principal e da parte aérea com o auxílio de uma régua graduada em centímetros, calculando-se o comprimento médio por plântula, em cada repetição; massa seca de plântulas - após a contagem final no teste de emergência, as plântulas anteriormente medidas foram submetidas, a secagem em estufa regulada a $65^{\circ} \mathrm{C}$ até atingirem peso constante, cujos resultados foram expressos em g/ plântula.

\section{Resultados e Discussão}

Pelos resultados obtidos foi possível verificar-se que houve diferença significativa entre os substratos utilizados, onde se constatou que a exceção do bioplant ${ }^{\circledR}\left(\mathrm{T}_{14}\right)$ e plugmix ${ }^{\circledR}\left(\mathrm{T}_{15}\right)$, cuja porcentagem de emergência foi de 88 e $85 \%$, respectivamente, os demais proporcionaram resultados elevados, sem diferirem estatisticamente entre si (Figura 1). Assim, percebe-se que esses substratos proporcionaram condições ideais de umidade e aeração, de forma que as sementes expressaram o seu máximo potencial germinativo. Resultados semelhantes foram obtidos por Moniz-Brito e Ayala-Osuña (2005) com Zyziphus joazeiro Mart., quando verificaram que o substrato terra vegetal + vermiculita proporcionou um aumento significativo na porcentagem de emergência de plântulas, em relação aos demais substratos utilizados (terra vegetal, terra vegetal + areia, e terra vegetal + serragem). Andrade et al. (2000) também verificaram que os substratos solo e vermiculita foram responsáveis por elevados percentuais de germinação em sementes de Genipa americana $\mathrm{L}$.

Provavelmente estes substratos tenham reunido características necessárias de um bom substrato para germinação, tais como porosidade e esterilidade, uma vez que uma boa porosidade permite o movimento de água e ar no mesmo, o que favorece a germinação. Para Simão (1971) a esterilidade do substrato seria outro fator importante para o aumento na taxa de germinação das sementes, uma vez que não serviria como fonte de patógenos de solo, os quais poderiam afetar a mesma e o estabelecimento das plântulas.

Essa diferença na germinação em função do substrato ou de alguma propriedade do mesmo (esterilidade, porosidade, capacidade de retenção de água, entre outros) também foi relatada por Nogueira; Albuquerque e Silva Junior (2003), em estudos realizados com Hancornia speciosa Gomes, quando observaram que o substrato areia esterilizada em autoclave proporcionou maior porcentagem de germinação quando comparada aos demais substratos testados (solo natural coletado em pomar espontâneo da espécie e mistura de húmus, areia e terriço vegetal, na proporção de 2:4:4 v/v). 


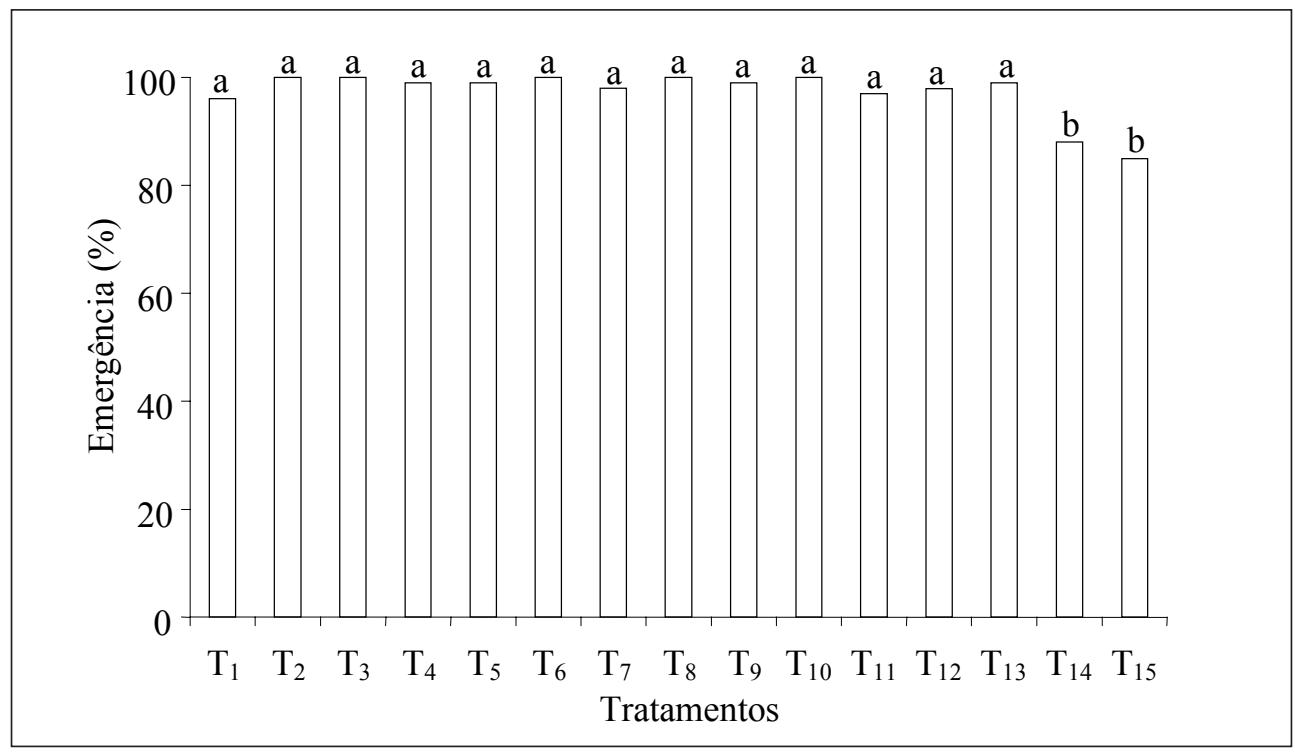

Figura 1. Emergência de plântulas mulungu, em função de diferentes substratos. Areia lavada $\left(\mathrm{T}_{1}\right)$; areia lavada + vermiculita na proporção de 1:1 $\left(\mathrm{T}_{2}\right), 3: 1\left(\mathrm{~T}_{3}\right)$ e 1:3 $\left(\mathrm{T}_{4}\right)$; terra vegetal $\left(\mathrm{T}_{5}\right)$, terra vegetal + areia lavada na proporção de 1:1 $\left(\mathrm{T}_{6}\right), 3: 1\left(\mathrm{~T}_{7}\right)$ e 1:3 $\left(\mathrm{T}_{8}\right)$, terra vegetal + vermiculita na proporção de 1:1 $\left(\mathrm{T}_{9}\right), 3: 1\left(\mathrm{~T}_{10}\right)$ e 1:3 $\left(\mathrm{T}_{11}\right)$, vermiculita $\left(\mathrm{T}_{12}\right)$, bioclone ${ }^{\circledR}\left(\mathrm{T}_{13}\right)$, bioplant ${ }^{\circledR}\left(\mathrm{T}_{14}\right)$ e plugmix ${ }^{\circledR}\left(\mathrm{T}_{15}\right)$.

CV $(\%)-2,39$.

Médias seguidas de mesma letra não diferem estatisticamente entre si, pelo teste de Scott Knott, ao nível de 5\% de probabilidade.

No presente trabalho, as sementes do substrato vermiculita apresentaram uma porcentagem média de emergência de $98 \%$. Trabalhos realizados por Ramos, Mendonça e Paula (2003) com sementes de Zeyhera tuberculosa Bur e por Melo, Mendonça e Mendes (2004) com sementes de Hymenaea intermedia var. adenotricha (Ducke) Lee \& Lang também demonstram a eficácia da vermiculita na germinação e emergência de plântulas. Andrade et al. (2000) verificaram na germinação de sementes de Genipa americana, em vermiculita, que substratos constituídos por partículas maiores apresentam maior espaço vazio, menor densidade aparente (ou menor grau de compactação), maior arejamento e, portanto, maiores facilidades para a emergência das plântulas.

Por sua vez, Carvalho Filho et al. (2003) semearam sementes de Hymenaea courbaril L nos substratos solo; solo + esterco (2:1); solo + areia (1:1) e solo + areia + esterco (1:2:1) e verificaram que as diferentes misturas de substratos não influenciaram no processo de emergência, uma vez que não houve diferenças significativas entre as mesmas

Quanto à primeira contagem de emergência (Figura 2), os menores valores $(40,79,81$ e $85 \%$, respectivamente) foram obtidos com as sementes do substrato plugmix ${ }^{\circledR}\left(\mathrm{T}_{15}\right)$, seguidas por aquelas do bioplant ${ }^{\circledR}\left(\mathrm{T}_{14}\right)$, areia lavada + vermiculita 1:1 $\left(\mathrm{T}_{1}\right) \mathrm{e}$ terra vegetal + areia lavada 1:1 $\left(\mathrm{T}_{6}\right)$. Os maiores valores de vigor (91 a 99\%), na primeira contagem foram obtidos com as sementes dos demais substratos utilizados: areia lavada + vermiculita na proporção de 1:1 $\left(\mathrm{T}_{2}\right), 3: 1\left(\mathrm{~T}_{3}\right)$ e 1:3 $\left(\mathrm{T}_{4}\right)$; terra vegetal $\left(\mathrm{T}_{5}\right)$, terra vegetal + areia lavada na proporção de $3: 1\left(\mathrm{~T}_{7}\right)$ e 1:3 $\left(\mathrm{T}_{8}\right)$, terra vegetal + vermiculita na proporção de 1:1 $\left(\mathrm{T}_{9}\right), 3: 1\left(\mathrm{~T}_{10}\right)$ e 1:3 $\left(\mathrm{T}_{11}\right)$, vermiculita $\left(\mathrm{T}_{12}\right)$, bioclone ${ }^{\circledR}\left(\mathrm{T}_{13}\right)$. Mais uma vez verifica-se que os substratos bioplant ${ }^{\circledR}$ e plugmix ${ }^{\circledR}$ não se mostraram adequados para condução de testes de emergência com sementes de mulungu, provavelmente devido a uma baixa capacidade de retenção de água, aliada a uma aeração deficiente (pouco oxigênio). 


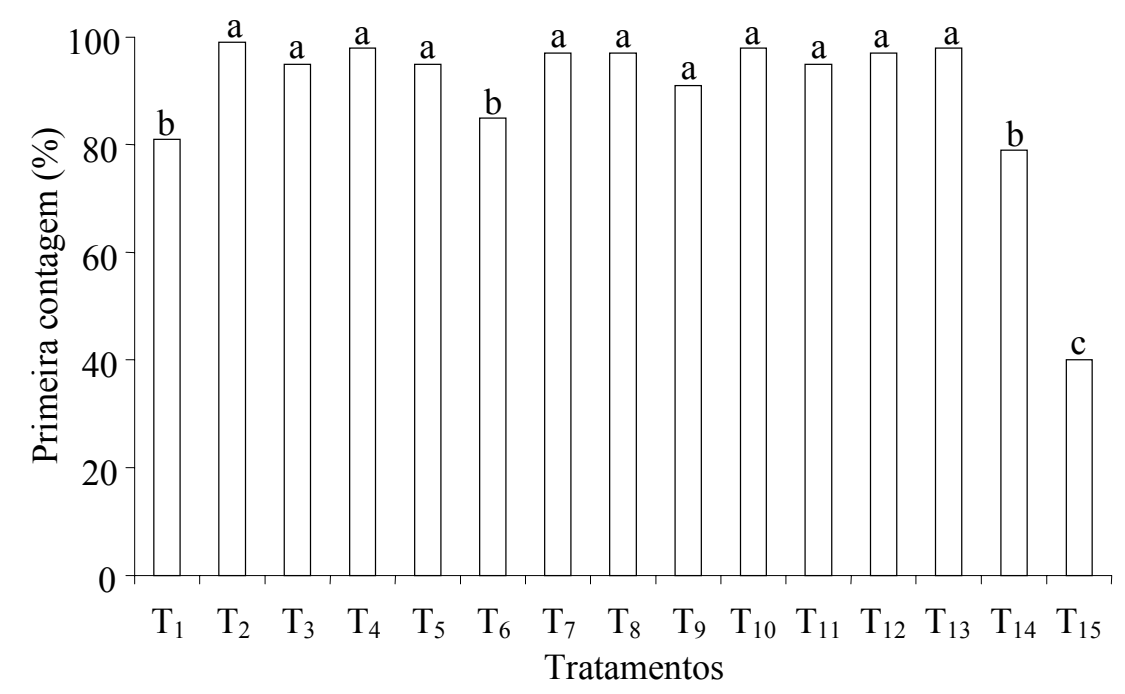

Figura 2. Primeira contagem de emergência de plântulas de mulungu, em função de diferentes substratos. Areia lavada $\left(\mathrm{T}_{1}\right)$; areia lavada + vermiculita na proporção de 1:1 $\left(\mathrm{T}_{2}\right), 3: 1\left(\mathrm{~T}_{3}\right)$ e 1:3 $\left(\mathrm{T}_{4}\right)$; terra vegetal $\left(\mathrm{T}_{5}\right)$, terra vegetal + areia lavada na proporção de 1:1 $\left(\mathrm{T}_{6}\right), 3: 1\left(\mathrm{~T}_{7}\right)$ e 1:3 $\left(\mathrm{T}_{8}\right)$, terra vegetal + vermiculita na proporção de 1:1 $\left(\mathrm{T}_{9}\right), 3: 1\left(\mathrm{~T}_{10}\right)$ e 1:3 $\left(\mathrm{T}_{11}\right)$,

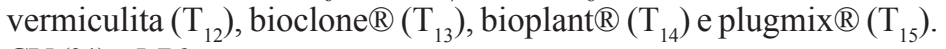

CV $(\%)-5,76$.

Médias seguidas de mesma letra não diferem estatisticamente entre si, pelo teste de Scott Knott, ao nível de 5\% de probabilidade.

Com relação ao índice de velocidade de emergência (Figura 3), os menores valores (3,89 e 3,20 , respectivamente) também foram registrados nas sementes dos substratos bioplant ${ }^{\circledR}\left(\mathrm{T}_{14}\right)$ e plugmix ${ }^{\circledR}\left(T_{15}\right)$, enquanto as sementes semeadas nos substratos areia lavada + vermiculita $1: 1,3: 1$ e 1:3 $\left(\mathrm{T}_{2}, \mathrm{~T}_{3}\right.$ e $\mathrm{T}_{4}$, respectivamente), terra vegetal + areia lavada $3: 1$ e $1: 3\left(\mathrm{~T}_{7}\right.$ e $\mathrm{T}_{8}$, respectivamente) e terra vegetal + vermiculita 3:1 $\left(\mathrm{T}_{10}\right)$ foram responsáveis pelos maiores índices de velocidade de emergência $(5,00 ; 5,09 ; 4,92 ; 5,04 ; 4,87$ e 4, 95, respectivamente). Resultados semelhantes foram obtidos por Andrade et al. (2000) quando verificaram que os substratos solo e vermiculita proporcionaram elevados índices de velocidade de germinação de sementes de Genipa americana L.

Vários autores relataram que as propriedades físicas e químicas da vermiculita possibilitam uma alta capacidade de retenção de água e condições ideais de aeração, tornando-o um substrato adequado para a utilização em ensaios de germinação (ANDRADE et al., 1999; ANDRADE et al., 2000; ARAÚJO; OLIVEIRA; COSTA, 1991). Por isso, os melhores resultados obtidos nos substratos que continham vermiculita e areia devem-se, provavelmente, a um bom suprimento de água e a uma aeração adequada.

Em contrapartida, Andrade et al. (1999) trabalhando com palmiteiro, encontraram valores de índice de velocidade de germinação mais altos nos substratos que continham vermiculita, enquanto Scalon et al. (2003) obtiveram maiores índices de velocidade de germinação em sementes de Caesalpinia pelthophoroides Benth., quando utilizaram o substrato terra vegetal. 


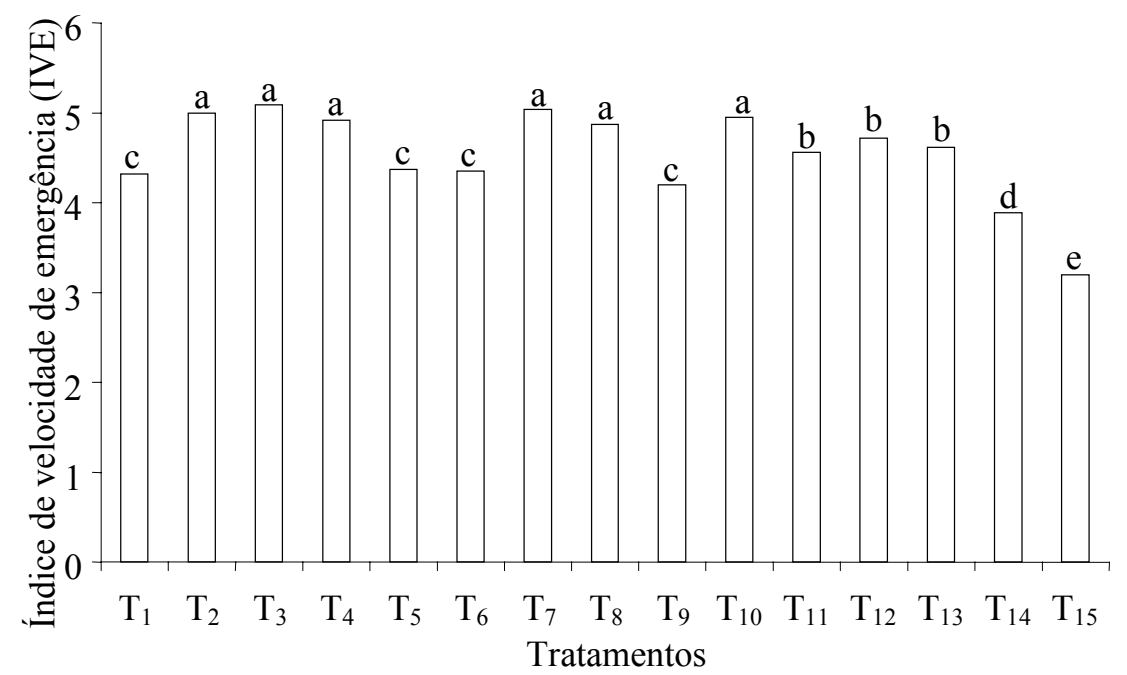

Figura 3. Índice de velocidade de emergência de plântulas de mulungu, em função de diferentes substratos. Areia lavada $\left(\mathrm{T}_{1}\right)$; areia lavada + vermiculita na proporção de 1:1 $\left(\mathrm{T}_{2}\right), 3: 1\left(\mathrm{~T}_{3}\right)$ e 1:3 $\left(\mathrm{T}_{4}\right)$; terra vegetal $\left(\mathrm{T}_{5}\right)$, terra vegetal + areia lavada na proporção de 1:1 $\left(\mathrm{T}_{6}\right), 3: 1\left(\mathrm{~T}_{7}\right)$ e 1:3 $\left(\mathrm{T}_{8}\right)$, terra vegetal + vermiculita na proporção de 1:1 $\left(\mathrm{T}_{9}\right), 3: 1\left(\mathrm{~T}_{10}\right)$ e 1:3 $\left(\mathrm{T}_{11}\right)$, vermiculita $\left(\mathrm{T}_{12}\right)$, bioclone ${ }^{\circledR}\left(\mathrm{T}_{13}\right)$, bioplant ${ }^{\circledR}\left(\mathrm{T}_{14}\right)$ e plugmix ${ }^{\circledR}\left(\mathrm{T}_{15}\right)$.

CV $(\%)-3,95$.

Médias seguidas de mesma letra não diferem estatisticamente entre si, pelo teste de Scott Knott, ao nível de 5\% de probabilidade.

De acordo com os dados da Figura 4 constatouse que nos substratos areia lavada + vermiculita 1:3 $\left(\mathrm{T}_{4}\right)$ e terra vegetal + vermiculita 1:1 $\left(\mathrm{T}_{9}\right)$ as sementes de mulungu apresentaram uma freqüência relativa de emergência de 70 e $80 \%$ no quinto e sexto dia de incubação, respectivamente, significando uma grande uniformidade na emergência das plântulas do referido tratamento.

Os substratos areia lavada $\left(\mathrm{T}_{1}\right)$ e terra vegetal + areia lavada $\left(\mathrm{T}_{6}\right)$ também demonstraram certa sincronização no processo germinativo das sementes, uma vez que a frequência relativa foi de 51 e $66 \%$ no sexto dia após a semeadura, havendo apenas um pequeno deslocamento a esquerda do tempo médio. Resultados semelhantes foram obtidos com as sementes dos substratos areia lavada + vermiculita 3:1 $\left(\mathrm{T}_{3}\right)$ e terra vegetal + areia lavada 3:1 $\left(\mathrm{T}_{7}\right)$ com uma frequência de 52 e $54 \%$ no quinto dia de incubação, enquanto nos substratos areia lavada + vermiculita $1: 1\left(\mathrm{~T}_{2}\right)$, terra vegetal + areia lavada $1: 3$ $\left(\mathrm{T}_{8}\right)$, terra vegetal + vermiculita $3: 1\left(\mathrm{~T}_{10}\right)$, vermiculita $\left(\mathrm{T}_{12}\right)$, bioclone ${ }^{\circledR}\left(\mathrm{T}_{13}\right)$ e bioplant ${ }^{\circledR}\left(\mathrm{T}_{14}\right)$, o processo germinativo das sementes foi menos sincronizado. No entanto, no plugmix ${ }^{\circledR}\left(\mathrm{T}_{15}\right)$ houve um grande deslocamento para esquerda e direita do tempo médio, respectivamente (Figura 4). De uma forma geral, o deslocamento da linha poligonal para a direita ou esquerda do tempo médio evidencia um atraso no processo germinativo, em conseqüência da redução do vigor das sementes.

Analisando-se os dados da figura 5, observa-se, que as plântulas originadas das sementes dos substratos areia lavada + vermiculita 1:1 $\left(\mathrm{T}_{2}\right)$, areia lavada + vermiculita 3:1 $\left(\mathrm{T}_{3}\right)$, bioclone ${ }^{\circledR}\left(\mathrm{T}_{13}\right)$ e bioplant ${ }^{\circledR}\left(\mathrm{T}_{14}\right)$ encontravam-se com raízes mais compridas, com valores médios de 13,53; 13,00; 12,77 e 12,97 cm, respectivamente. A exemplo do registrado para as características descritas anteriormente, o tratamento $T_{15}$ (plugmix ${ }^{\circledR}$ ) também proporcionou plântulas com menor comprimento da raiz primária $(7,70 \mathrm{~cm})$. Iossi et al. (2003) também constataram que os substratos areia e vermiculita foram responsáveis pelo maior comprimento da raiz primária de plântulas de $P$. roebelenii. 


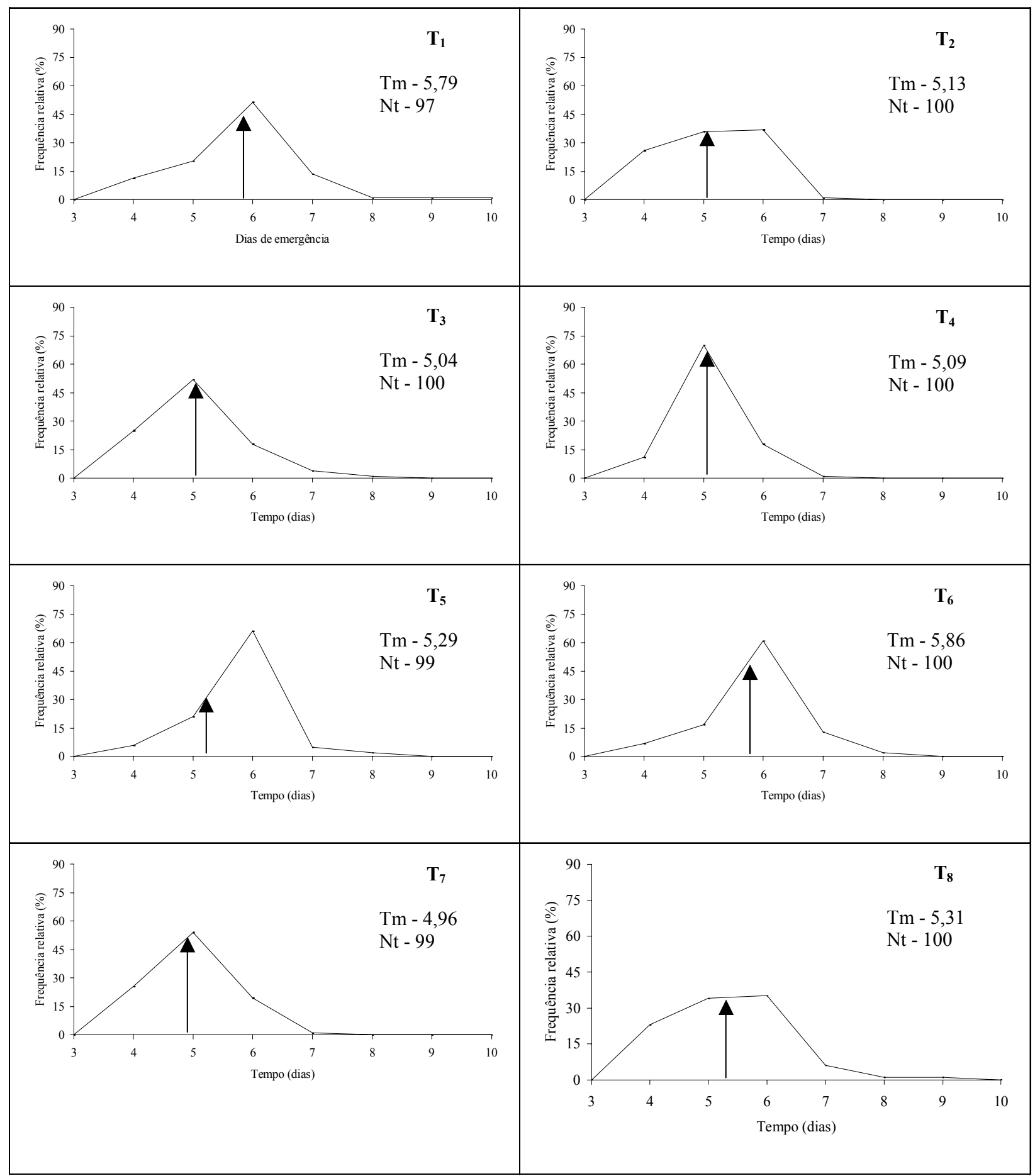

continua 
continuação

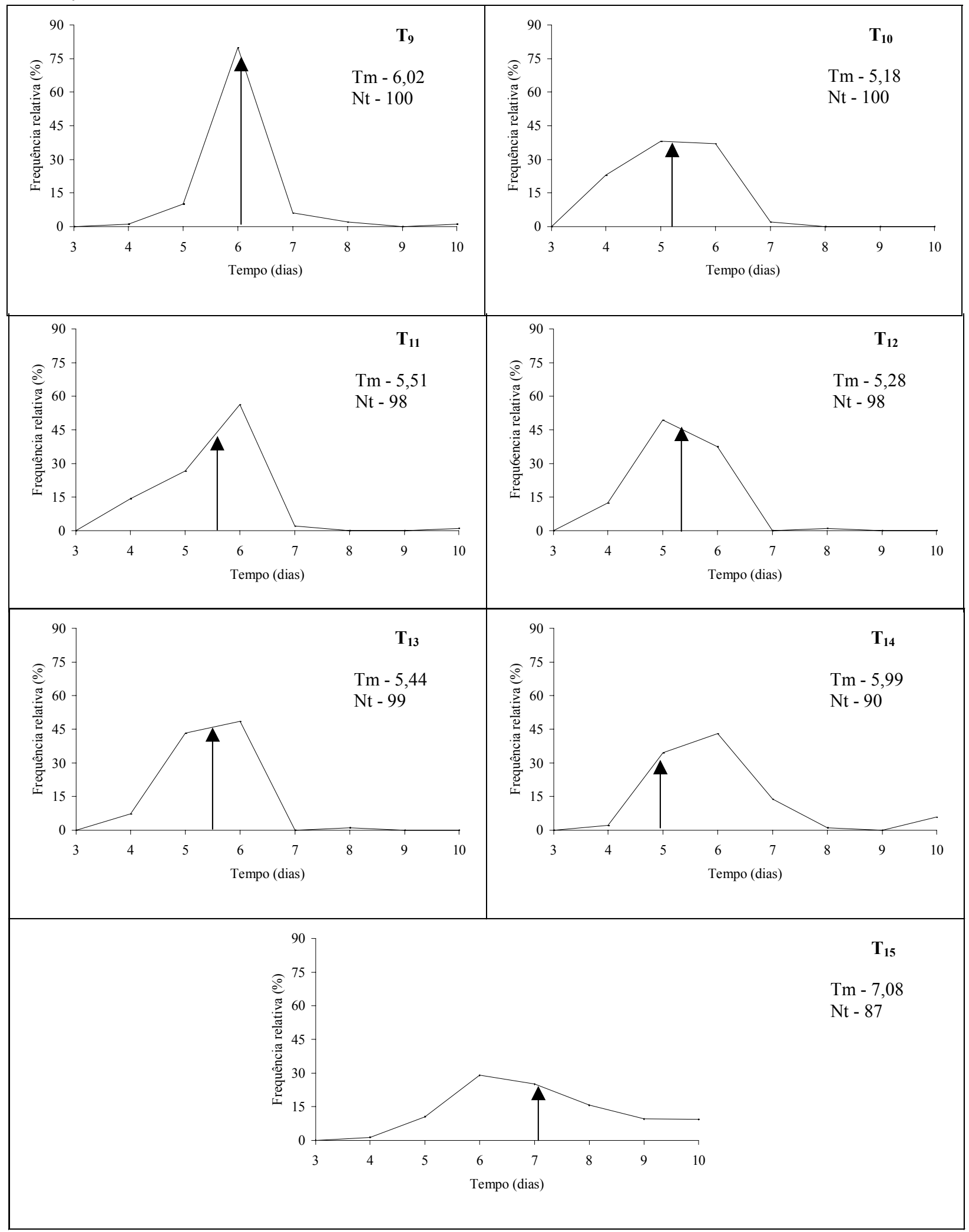

Figura 4. Freqüência relativa da emergência de plântulas de mulungu oriundas de sementes submetidas a diferentes substratos. $(\mathrm{Nt}=$ número total de sementes germinadas e $\mathrm{Tm}=$ tempo médio de emergência $)$. Areia lavada $\left(\mathrm{T}_{1}\right)$; areia lavada + vermiculita na proporção de 1:1 $\left(\mathrm{T}_{2}\right), 3: 1\left(\mathrm{~T}_{3}\right)$ e 1:3 $\left(\mathrm{T}_{4}\right)$; terra vegetal $\left(\mathrm{T}_{5}\right)$, terra vegetal + areia lavada na proporção de 1:1 $\left(\mathrm{T}_{6}\right), 3: 1\left(\mathrm{~T}_{7}\right)$ e 1:3 $\left(\mathrm{T}_{8}\right)$, terra vegetal + vermiculita na proporção de 1:1 $\left(\mathrm{T}_{9}\right), 3: 1\left(\mathrm{~T}_{10}\right)$ e 1:3 $\left(\mathrm{T}_{11}\right)$, vermiculita $\left(T_{12}\right)$, bioclone $₫\left(T_{13}\right)$, bioplant $\AA\left(T_{14}\right)$ e plugmix $®\left(T_{15}\right)$. 


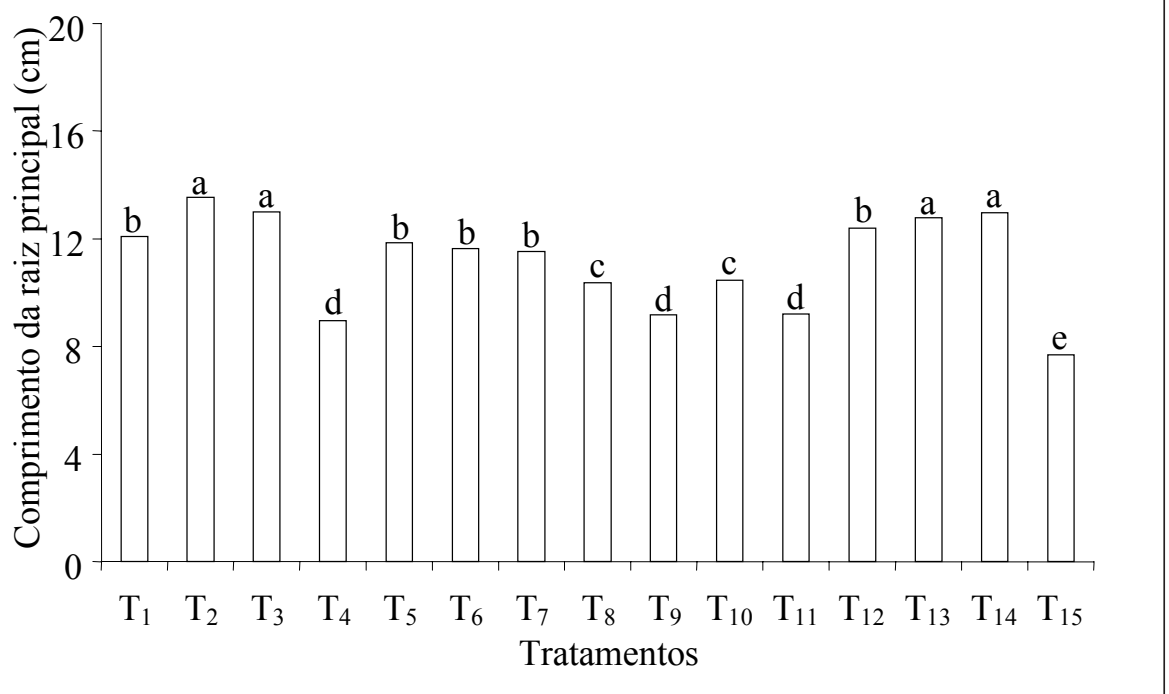

Figura 5. Comprimento da raiz principal de plântulas de mulungu, oriundas de sementes semeadas em diferentes substratos. Areia lavada $\left(\mathrm{T}_{1}\right)$; areia lavada + vermiculita na proporção de 1:1 $\left(\mathrm{T}_{2}\right), 3: 1\left(\mathrm{~T}_{3}\right)$ e 1:3 $\left(\mathrm{T}_{4}\right)$; terra vegetal $\left(\mathrm{T}_{5}\right)$, terra vegetal + areia lavada na proporção de 1:1 $\left(\mathrm{T}_{6}\right), 3: 1\left(\mathrm{~T}_{7}\right)$ e 1:3 $\left(\mathrm{T}_{8}\right)$, terra vegetal + vermiculita na proporção de 1:1 $\left(\mathrm{T}_{9}\right), 3: 1\left(\mathrm{~T}_{10}\right)$ e 1:3 $\left(\mathrm{T}_{11}\right)$, vermiculita $\left(\mathrm{T}_{12}\right)$, bioclone ${ }^{\circledR}\left(\mathrm{T}_{13}\right)$, bioplant ${ }^{\circledR}\left(\mathrm{T}_{14}\right)$ e plugmix ${ }^{\circledR}\left(\mathrm{T}_{15}\right)$.

CV $(\%)-5,09$.

Médias seguidas de mesma letra não diferem estatisticamente entre si, pelo teste de Scott Knott, ao nível de 5\% de probabilidade.

Quanto ao comprimento da parte aérea (Figura $6)$, os maiores valores $(12,93$ e $13,12 \mathrm{~cm}$, respectivamente) foram obtidos com as plântulas dos tratamentos $\mathrm{T}_{3}$ (areia lavada + vermiculita 3:1) e $\mathrm{T}_{10}$ (terra vegetal + vermiculita 3:1) e, os menores $(9,90$ $\mathrm{cm}$ ), para as plântulas do tratamento $\mathrm{T}_{15}$ (plugmix ${ }^{\circledR}$ ). Santos et al. (1994) também verificaram, em Mimosa caesalpiniaefolia Benth., que o substrato areia proporcionou os melhores resultados para comprimento de raiz e de parte aérea. Resultados semelhantes foram obtidos por Moniz-Brito e AyalaOsuña (2005) quando constataram que o substrato vermiculita proporcionou maior altura da parte aérea e comprimento radicular de plântulas de Zyziphus joazeiro Mart. No entanto, Iossi et al. (2003) relataram que o menor comprimento da parte aérea de plântulas de $P$. roebelenii foi obtido com o substrato vermiculita.
Os substratos que proporcionaram maior comprimento das plântulas possivelmente atenderam todos os requisitos para uma emergência rápida $\mathrm{e}$ uniforme, bem como um crescimento inicial satisfatório. De acordo com Martins, Nakagawa e Bovi (1999), plântulas que emergem mais rápido podem tornar-se menos vulneráveis as condições adversas do meio por passarem menos tempo nos estádios iniciais de desenvolvimento.

Ocorreram diferenças significativas entre os resultados de massa seca das raízes de plântulas de mulungu, oriundas de sementes semeadas em diferentes substratos, onde os menores valores $(0,029$ e $0,021 \mathrm{~g} /$ planta, respectivamente) foram obtidos com os substratos bioplant ${ }^{\circledR}\left(\mathrm{T}_{14}\right)$ e plugmix ${ }^{\circledR}\left(\mathrm{T}_{15}\right)$, tornando-os menos indicados para o teste de emergência dessas plântulas, uma vez que não favoreceram o desenvolvimento do sistema radicular das mesmas (Figura 7). 


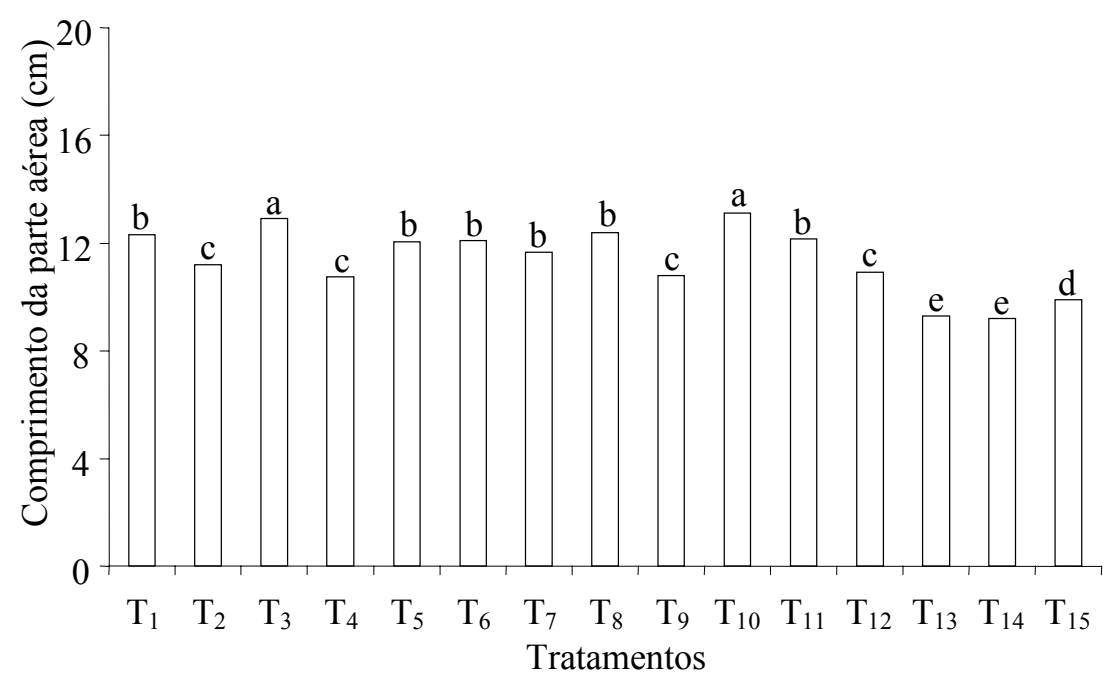

Figura 6. Comprimento da parte aérea de plântulas de mulungu, oriundas de sementes semeadas em diferentes substratos. Areia lavada $\left(\mathrm{T}_{1}\right)$; areia lavada + vermiculita na proporção de 1:1 $\left(\mathrm{T}_{2}\right), 3: 1\left(\mathrm{~T}_{3}\right)$ e 1:3 $\left(\mathrm{T}_{4}\right)$; terra vegetal $\left(\mathrm{T}_{5}\right)$, terra vegetal + areia lavada na proporção de 1:1 $\left(\mathrm{T}_{6}\right), 3: 1\left(\mathrm{~T}_{7}\right)$ e $1: 3\left(\mathrm{~T}_{8}\right)$, terra vegetal + vermiculita na proporção de 1:1 $\left(\mathrm{T}_{9}\right), 3: 1\left(\mathrm{~T}_{10}\right)$ e 1:3 $\left(\mathrm{T}_{11}\right)$, vermiculita $\left(\mathrm{T}_{12}\right)$, bioclone ${ }^{\circledR}\left(\mathrm{T}_{13}\right)$, bioplant ${ }^{\circledR}\left(\mathrm{T}_{14}\right)$ e plugmix ${ }^{\circledR}\left(\mathrm{T}_{15}\right)$.

$\mathrm{CV}(\%)-3,93$.

Médias seguidas de mesma letra não diferem estatisticamente entre si, pelo teste de Scott Knott, ao nível de 5\% de probabilidade.

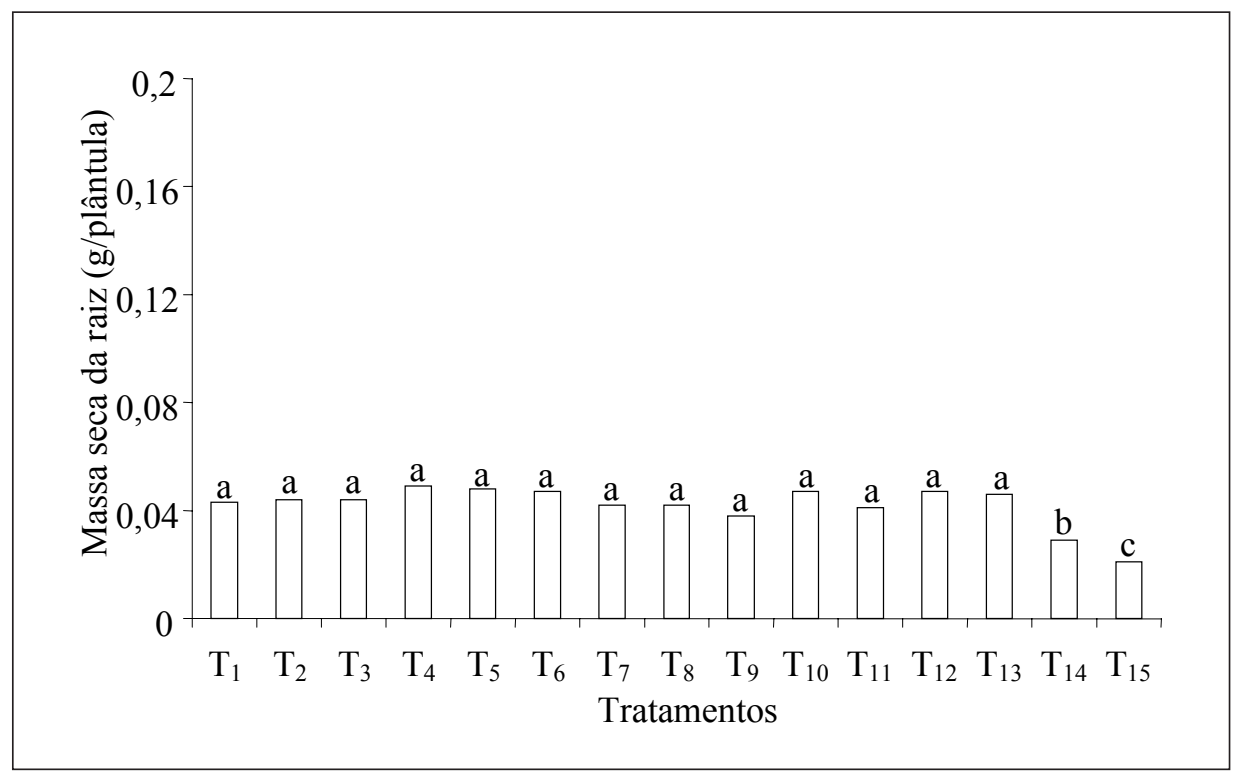

Figura 7. Massa seca das raízes de plântulas de mulungu, oriundas de sementes semeadas em diferentes substratos. Areia lavada $\left(\mathrm{T}_{1}\right)$; areia lavada + vermiculita na proporção de 1:1 $\left(\mathrm{T}_{2}\right), 3: 1\left(\mathrm{~T}_{3}\right)$ e 1:3 $\left(\mathrm{T}_{4}\right)$; terra vegetal $\left(\mathrm{T}_{5}\right)$, terra vegetal + areia lavada na proporção de 1:1 $\left(\mathrm{T}_{6}\right), 3: 1\left(\mathrm{~T}_{7}\right)$ e 1:3 $\left(\mathrm{T}_{8}\right)$, terra vegetal + vermiculita na proporção de 1:1 $\left(\mathrm{T}_{9}\right), 3: 1\left(\mathrm{~T}_{10}\right)$ e 1:3 $\left(\mathrm{T}_{11}\right)$, vermiculita $\left(\mathrm{T}_{12}\right)$, bioclone ${ }^{\circledR}\left(\mathrm{T}_{13}\right)$, bioplant ${ }^{\circledR}\left(\mathrm{T}_{14}\right)$ e plugmix ${ }^{\circledR}\left(\mathrm{T}_{15}\right)$.

CV $(\%)-11,76$

Médias seguidas de mesma letra não diferem estatisticamente entre si, pelo teste de Scott Knott, ao nível de 5\% de probabilidade. 
Para a massa seca da parte aérea (Figura 8) constatou-se que os maiores pesos $(0,164 ; 0,166$; 0,$162 ; 0,176$ e $0,159 \mathrm{~g} /$ plântula, respectivamente) foram obtidos quando se utilizou os substratos areia $\left(\mathrm{T}_{1}\right)$, areia + vermiculita $1: 1$ e $3: 1\left(\mathrm{~T}_{2}\right.$ e $\mathrm{T}_{3}$, respectivamente), terra vegetal + areia $1: 3\left(\mathrm{~T}_{8}\right)$, terra vegetal + vermiculita $3: 1\left(\mathrm{~T}_{10}\right)$ e bioclone ${ }^{\circledR}\left(\mathrm{T}_{13}\right)$, sendo a terra vegetal + vermiculita $1: 1\left(\mathrm{~T}_{9}\right)$ e o bioplant ${ }^{\circledR}\left(T_{14}\right)$ os piores substratos, seguidos pelo plugmix ${ }^{\circledR}\left(T_{15}\right)$, com valores médios de $0,133,0,129$ e $0,115 \mathrm{~g} /$ plântula, respectivamente. Os substratos bioclone ${ }^{\circledR}$ e plugmix ${ }^{\circledR}$ provavelmente mantiveram as menores quantidades de água ou pouco oxigênio disponível, o que acabou afetando negativamente o desenvolvimento das plântulas.
Moniz-Brito e Ayala-Osuña (2005) também verificaram que os maiores resultados do peso de massa seca das plântulas de Zyziphus joazeiro Mart., ocorreram com o uso da vermiculita. Já Iossi et al. (2003) constataram menores pesos de massa seca do sistema radicular e da parte aérea de plântulas de $P$. roebelenii quando utilizaram o substrato vermiculita.

Santos et al. (1994) verificaram em sementes de sabiá (Mimosa caesalpiniaefolia Benth.), que a areia, ao contrário deste ensaio, foi o substrato que proporcionou os melhores resultados para altura de plântulas e comprimento de raiz. Verificaram ainda que, para o peso de massa fresca e seca da parte aérea, o substrato areia proporcionou maiores valores que os substratos terriço e casca de arroz.

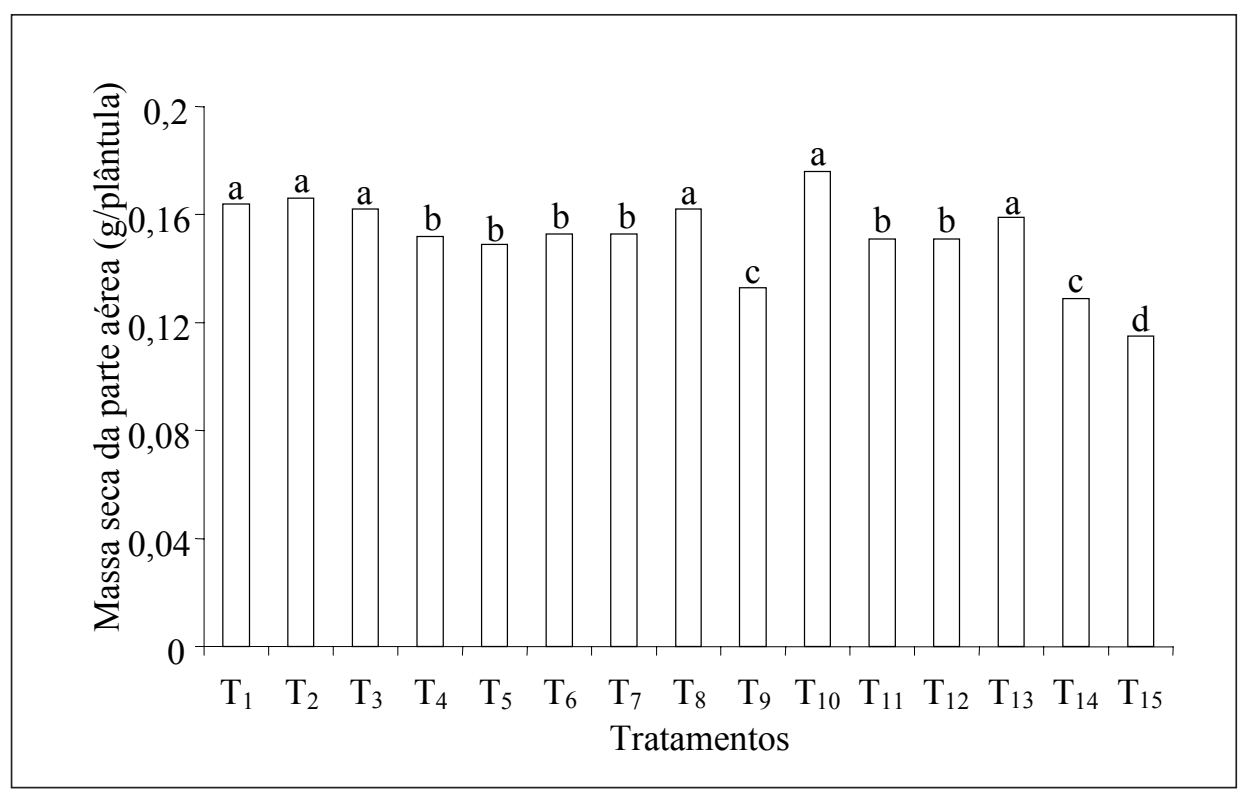

Figura 8. Massa seca da parte aérea de plântulas de mulungu, oriundas de sementes semeadas em diferentes substratos. Areia lavada $\left(\mathrm{T}_{1}\right)$; areia lavada + vermiculita na proporção de 1:1 $\left(\mathrm{T}_{2}\right), 3: 1\left(\mathrm{~T}_{3}\right)$ e 1:3 $\left(\mathrm{T}_{4}\right)$; terra vegetal $\left(\mathrm{T}_{5}\right)$, terra vegetal + areia lavada na proporção de 1:1 $\left(\mathrm{T}_{6}\right), 3: 1\left(\mathrm{~T}_{7}\right)$ e 1:3 $\left(\mathrm{T}_{8}\right)$, terra vegetal + vermiculita na proporção de 1:1 $\left(\mathrm{T}_{9}\right), 3: 1\left(\mathrm{~T}_{10}\right)$ e 1:3 $\left(\mathrm{T}_{11}\right)$, vermiculita $\left(\mathrm{T}_{12}\right)$, bioclone ${ }^{\circledR}\left(\mathrm{T}_{13}\right)$, bioplant ${ }^{\circledR}\left(\mathrm{T}_{14}\right)$ e plugmix ${ }^{\circledR}\left(\mathrm{T}_{15}\right)$.

$\mathrm{CV}(\%)-6,62$.

Médias seguidas de mesma letra não diferem estatisticamente entre si, pelo teste de Scott Knott, ao nível de 5\% de probabilidade. 


\section{Conclusão}

O substrato areia proporcionou os melhores resultados para o comprimento da raiz e da parte aérea.

Os substratos areia e vermiculita apresentaram plântulas com maior comprimento de raiz.

Os substratos comerciais bioplant ${ }^{\circledR}$ e plugmix ${ }^{\circledR}$ foram responsáveis pelos piores desempenhos relativos à emergência e desenvolvimento das plântulas.

\section{Referências}

ABREU, D. C.; NOGUEIRA, A. C.; MEDEIROS, A. C. S. Efeito do substrato e da temperatura na germinação de sementes de cataia (Drimys brasiliensis Miers. Winteraceae). Revista Brasileira de Sementes, Pelotas, v. 27, n. 1, p. 149-157, 2005.

ALBUQUERQUE, M. C. F.; RODRIGUES, T. J. D.; MINOHARA, L.; TEBALDI, N. D.; SILVA, L. M. M. Influência da temperatura e do substrato na germinação de sementes de saguaraji (Colubrina glandulosa Perk. Rhamnaceae). Revista Brasileira de Sementes, Brasília, v. 20, n. 2, p. 346-349, 1998.

ANDRADE, A. C. S.; LOUREIRO, M. B.; SOUZA, A. D. O.; RAMOS, F. N.; CRUZ, A. P. M. Reavaliação do efeito do substrato e da temperatura na germinação de sementes de palmiteiro (Euterpe edulis Mart). Revista Árvore, Viçosa, v. 23, n. 3, p. 279-283, 1999.

ANDRADE, A. C. S.; PEREIRA, T. S.; FERNANDES, M. J; CRUZ, A. P. M.; CARVALHO, A. S. R. Substrato, temperatura de germinação e desenvolvimento pósseminal de sementes de Dalbergia nigra. Pesquisa Agropecuária Brasileira, Brasília, v. 41, n. 3, p. 517-523, 2006.

ANDRADE, A. C. S.; SOUZA, A. F.; RAMOS, F. N.; PEREIRA, T. S.; CRUZ, A. P. M. Germinação de sementes de jenipapo: temperatura, substrato e morfologia do desenvolvimento pós-seminal. Pesquisa Agropecuária Brasileira, Brasília, v. 35, n. 3, p. 609-615, 2000.

ARAÚJO, P. S. R.; OLIVEIRA, F. J.; COSTA, M. C. B. Avaliação preliminar da germinação de sementes de feijões (alado e jacatupé). Pesquisa Agropecuária Brasileira, Brasília, v. 26, n. 6, p. 857-861, 1991.

BEZERRA, A. M. E.; MOMENTÉ, V. G.; ARAÚJO, E. C.; MEDEIROS FILHO, S. Germinação e desenvolvimento de plântulas de melão-de-são-caetano em diferentes ambientes e substratos. Ciência Agronômica, Fortaleza, v. 33, n. 1, p. 39-44, 2002.
BILIA, D. A. C.; BARBEDO, C. J.; MALUF, A. M. Germinação de diásporos de canela-preta (Ocotea corymbosa (Meissn.) Mez - Lauraceae) em função da temperatura, do substrato e da dormência. Revista Brasileira de Sementes, Brasília, v. 20, n. 1, p. 189-194, 1998.

BRASIL. Ministério da Agricultura e Reforma Agrária. Regras para análise de sementes, Brasília: SNDA/DNDV/ CLAV, 1992.

CAMPOS, M. A. A.; UCHIDA, T. Influência do sombreamento no crescimento de mudas de três espécies amazônicas. Pesquisa Agropecuária Brasileira, Brasília, v. 37, n. 3, p. 281-288, 2002.

CARVALHO FILHO, J. L. S.; ARRIGONI-BLANK, M. F.; BLANK, A. F.; RANGEL, M. S. A. Produção de mudas de jatobá (Hymenaea courbaril L.) em diferentes ambientes, recipientes e composições de substratos. Cerne, Lavras, v. 9, n. 1, p. 109-118, 2003.

CARVALHO, N. M.; NAKAGAWA, J. Sementes: ciência, tecnologia e produção. Jaboticabal: FUNEP, 2000.

DANTAS, M. C.; OLIVEIRA, F. S.; BANDEIRA, S. M.; BATISTA, J. S.; SILVA JÚNIOR, C. D.; ALVES, P. B.; ANTONIOLLI, A. R.; MARCHIORO, M. Central nervous system effects of the crude extract of Erythrina velutina on rodents. Journal of Ethnopharmacology, Irlanda, v. 94, n. 1, p. 129-133, 2004.

HARTMANN, H. T.; KESTER, D. E.; DAVIES JUNIOR., F. T.; GENEVE, R. L. Plant propagation: principles and practices. 6.ed. New Jersey: Prentice Hall, 1997.

IOSSI, E.; SADER, R.; PIVETTA, K. F. L.; BARBOSA, J. C. Efeitos de substratos e temperaturas na germinação de sementes de tamareira-anã (Phoenix roebelenii O'Brien). Revista Brasileira de Sementes, Londrina, v. 25, n. 2, p. 63-69, 2003.

KURIHARA, D. L.; IMAÑA-ENCINAS, J.; PAULA, J. E. Levantamento da arborização do campus da universidade de Brasília. Cerne, Lavras, v. 11, n. 2, p. 127-136, 2005.

LABOURIAU, L. G.; VALADARES, M. E. B. On the germination of seed of Calotropis procera (Ait.) Ait. F. Anais da Academia Brasileira de Ciências, Rio de Janeiro, v. 48, n. 2, p. 263-284, 1976.

LOPES, J. C.; PEREIRA, M. D. Germinação de sementes de cubiu em diferentes substratos e temperaturas. Revista Brasileira de Sementes, Pelotas, v. 27, n. 2, p. 146-150, 2005.

LORENZI, H. Árvores brasileiras: manual de identificação e cultivo de plantas arbóreas nativas do Brasil. Nova Odessa: Instituto Plantarum. 2002. 
LORENZI, H.; MATOS, F. J. A. Plantas medicinais no Brasil: nativas e exóticas cultivadas. Nova Odessa: Instituto Plantarum de Estudos da Flora Ltda., 2002.

MACHADO, C. F.; OLIVEIRA, J. A.; DAVIDE, A. C.; GUIMARÃES, R. M. Metodologia para a condução do teste de germinação em sementes de ipê-amarelo (Tabebuia serratifolia (Vahl) Nicholson). Cerne, Lavras, v. 8, n. 2, p. 18-27, 2002.

MAGUIRE, J. D. Speed of germination - aid in selection and evaluation for seedling and vigour. Crop Science, Madison, v. 2, n. 2, p. 176-177, 1962.

MARCOS FILHO, J. Germinação de sementes, In: Atualização em produção de sementes. Campinas: Fundação Cargill, 1986. p.11-39.

MARTINS, C. C.; NAKAGAWA, J.; BOVI, M. L. Efeito da posição da semente no substrato e no crescimento inicial das plântulas de palmito-vermelho (Euterpe espiritosantensis Fernades - Palmae). Revista Brasileira de Sementes, Brasília, v. 21, n. 1, p. 164-173, 1999.

MEDEIROS, A. C. S.; ZANON, A. Efeitos do substrato e da temperatura na germinação de sementes de branquilho (Sebastiania commersoniana (Baillon) L.B. Smith \& R.J. Down) e de pinheiro-bravo (Podocarpus lambertii Klotzch ex NDL.). Boletim de Pesquisa Florestal, Colombo, n. 36, p. 21-28, 1998.

MELO, M. G. G; MENDONÇA, M. S.; MENDES, A. M. S. Análise morfológica de sementes, germinação e plântulas de jatobá (Hymenaea intermedia Ducke var. adenotricha (Ducke) Lee \& Lang.) (Leguminosae - Caesalpinioideae). Acta Amazonica, Manaus, v. 34, n. 1, p. 9-14, 2004.

MONIZ-BRITO, K. L.; AYALA-OSUÑA, J. T. Influência de diferentes substratos na germinação de sementes de Ziziphus joazeiro Mart., Rhamnaceae. Sitientibus Série Ciências Biológicas, Feira de Santana, v. 5, n. 2, p. 63-67, 2005.

NOGUEIRA, R. J. M. C.; ALBUQUERQUE, M. B.; SILVA JUNIOR, J. F. Efeito do substrato na emergência, crescimento e comportamento estomático em plântulas de mangabeira. Revista Brasileira de Fruticultura, Jaboticabal, v. 25, n. 1, p. 15-18, 2003.
OLIVEIRA, E. C.; PIÑA-RODRIGUES, F. C. M.; FIGLIOLIA, M. B. Proposta para a padronização de metodologias em análise de sementes florestais. Revista Brasileira de Sementes, Brasília, v. 11, n. 1/2/3, p. 1-42, 1989.

PEREZ, S. C. J. G. A.; FANTI, S. C.; CASALI, C. A. Influência do armazenamento, substrato, envelhecimento precoce e profundidade de semeadura na germinação de canafístula. Bragantia, Campinas, v. 58, n. 1, p. 57-68, 1999.

RAMOS. N. P.; MENDONÇA, E. A. F.; PAULA, R. C. Germinação de sementes de Zeyhera tuberculosa (Vell.) Bur. (ipê- felpudo). Revista Agricultura Tropical, Cuiabá, v. 7, n. 1, p. 41-52, 2003.

SANTOS, C. E.; ROBERTO, S. R.; MARTINS, A. B. G. Propagação do biribá (Rollinia mucosa) e sua utilização como porta-enxerto de pinha (Annona squamosa). Acta Scientirum Agronomy, Maringá, v. 27, n. 3, p. 433-436, 2005.

SANTOS, D. S. B.; SANTOS-FILHO, B. G.; TORRES, S. B.; FIRMINO, J. L.; SMIDERLE, O. J. Efeito do substrato e profundidade de semeadura na emergência e desenvolvimento de plântulas de sabiá. Revista Brasileira de Sementes, Brasília, v. 16, n. 1, p. 50-53, 1994.

SCALON, S. P. Q.; MUSSURY, R. M.; ALMEIDA, K. A.; RIGONI, M. R. Efeito do álcool e substrato na germinação de sementes de sibipiruna (Caesalpinia pelthophoroides Benth.) colhidas no chão e retiradas da vagem. Ciência e Agrotecnologia, Lavras, v. 27, n. 2, p. 389-392, 2003.

SIMÃO, S. Manual de fruticultura. São Paulo: Ceres, 1971.

TORRES, S. B.; MELLO, V. D. C. Germinação de sementes de gliricidia (Gliricidia sepium (Jacq.) Steud). Ciência Rural, Santa Maria, v. 24, n. 3, p. 631-632, 1994.

VARELA, V. P.; COSTA, S. S.; RAMOS, M. B. P. Influência da temperatura e do substrato na germinação de sementes de itaubarana (Acosmium nitens (Vog.) Yakovlev) Leguminosae, Caesalpinoideae. Acta Amazonica, Manaus, v. 35, n. 1, p. 35-39, 2005.

VIRTUOSO, S.; DAVET, A.; DIAS, J. F. G.; CUNICO, M. M.; MIGUEL, M. D.; OLIVEIRA, A. B.; MIGUEL, O. G. Estudo preliminar da atividade antibacteriana das cascas de Erythrina velutina Willd., Fabaceae (Leguminosae). Revista Brasileira de Farmacognosia, João Pessoa, v. 15, n. 2, p. 137-142, 2005. 